\title{
Managing Cold Temperature and Brittle Fracture Hazards in Pressure Vessels
}

\author{
Daniel J. Benac $\cdot$ Nicholas Cherolis $\cdot$ David Wood
}

Submitted: 25 November 2015/Published online: 4 January 2016

(C) ASM International 2016

\begin{abstract}
Brittle fractures of pressure vessels can be both catastrophic and costly. The intent of this article is to provide guidance in avoiding such failures by identifying some of the causes for cold embrittlement hazards and brittle fracture in pressure vessels. Selected examples will help illustrate the main factors that contribute to brittle fracture, through identifying brittle fracture features, and demonstrating the importance of coordination of materials and potential operating condition. This article also discusses how to assess existing equipment pressure vessels subject to cold conditions and brittle fracture concerns using the guidelines of API 579-1/ASME FFS-1, Part 3.
\end{abstract}

Keywords Brittle fracture - ASME/API 579 .

Pressure vessels $\cdot$ Chevron marks $\cdot$ Low toughness

\section{Introduction}

Brittle fractures in the aerospace, oil and gas, chemical industry, nuclear and fossil-fuel power generation, and other industries are not common. But when they occur, they may result in a sudden, unexpected, and catastrophic failure, followed by the potential release of chemicals, toxics, or even a fire or explosion. Therefore, awareness of cold temperature brittle fracture is essential for anyone working in such industries. It is the goal of this article to enable the reader to reduce the risk of brittle failure in pressure vessels by learning how to properly identify and manage potential cold temperature embrittlement and brittle fracture risks.

D. J. Benac $(\bowtie) \cdot$ N. Cherolis · D. Wood

Baker Engineering and Risk Consultants, Inc. (BakerRisk $\left.{ }^{\circledR}\right)$, 3330 Oakwell Court, Suite 100, San Antonio, TX 78218, USA e-mail: dbenac@bakerrisk.com
This article provides a historical perspective and reviews the sources for concern in the pressure vessel industry and pressure-containing equipment. Some of the distinctive fracture features in a brittle fracture of a pressure vessel are also discussed, as well as, methods for assessing the causes and potential hazards of brittle fracture, in order to mitigate or reduce the risk of a catastrophic failure due to cold temperature brittle fracture.

\section{Historic Examples}

Historic brittle fractures include the brittle fracture of 160 World War II liberty ships, which caused them to break in half during the winter months between 1943 and 1944, Fig. 1. Catastrophic failures of molasses storage tanks also occurred on two separate occasions, in 1919 and 1978. In 1919 , on a cold day, just 4 years after it was built, a giant storage tank ripped open, releasing a flood of molasses in the city of Boston, Fig. 2. Poor fabrication practices, low material toughness, and design practices contributed to the failures $[1,2]$.

In South Africa, a pressurized ammonia bullet-type tank operating near ambient conditions had required weld repairs near a dished head seam [3]. The tank had not been stress relieved at the time of manufacture, nor after the weld repairs. Later material testing also indicated poor toughness properties with the transition temperature above ambient conditions. While in service, an ammonia leak developed in the dished head, which apparently chilled the area so that a 4-foot portion of the dished head failed "in an explosive manner" [4].

These brittle fractures had tragic outcomes, leading to both personnel and economic losses. The lessons learned from these failures, as well as from other failures were 


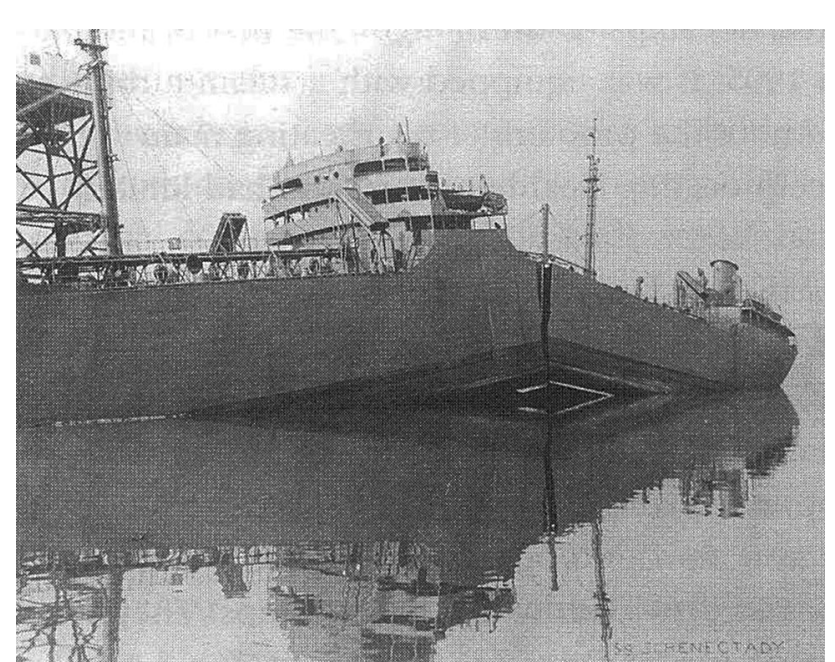

Fig. 1 Liberty ship Schenectady in the Portland shipyard split in two while still under construction in 1943

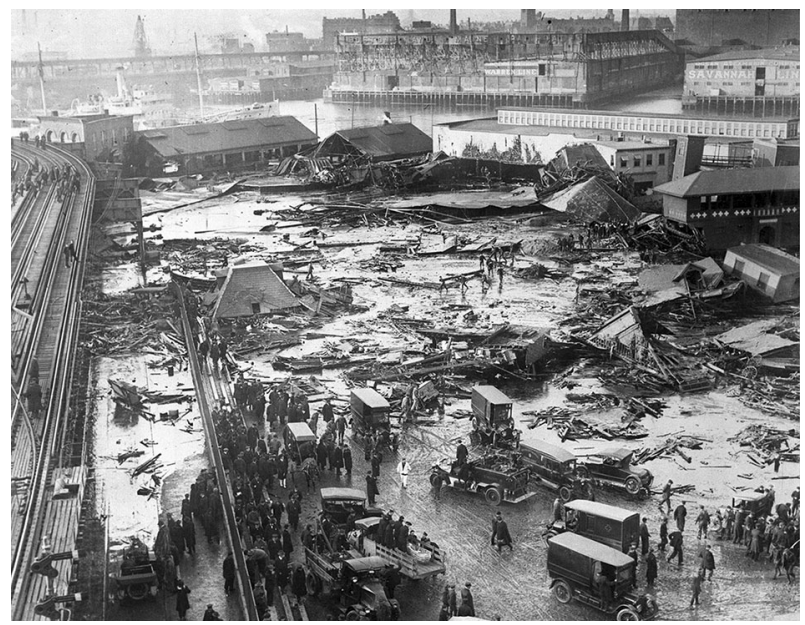

Fig. 2 Boston Molasses tank failure wrecked an entire neighborhood in January 1919

implemented into storage tank and ship-building fabrication to prevent brittle fractures. Brittle fracture is not limited to a large vessel or tank; it can also occur in a small bolt, a shaft, or a single plate of material. No matter what the component or equipment, no single component is insignificant, and brittle fractures should be avoided. No designer, operator, or user of equipment wants a brittle fracture, but it can and does occur in the commonly used carbon and low-alloy steels that make up the heat exchangers, towers, drums, and thick-plate pressure vessels.

\section{Brittle Fracture Defined}

Brittle fracture is defined as the sudden rapid fracture under stress where the material exhibits little or no evidence of

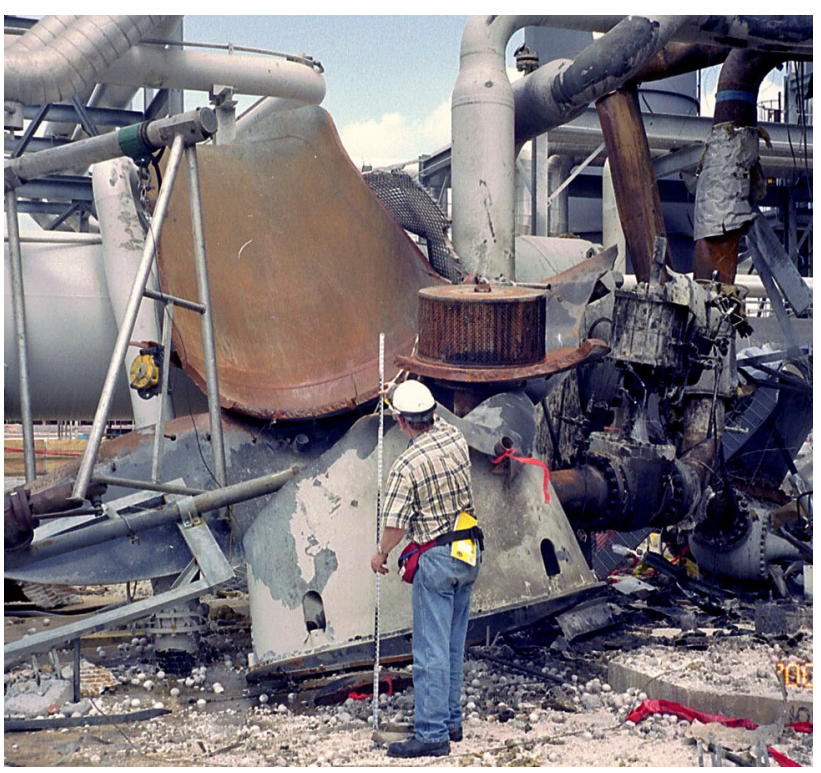

Fig. 3 Brittle fracture of a pressure vessel is sudden and catastrophic, resulting in loss of containment of product and energetic fragmentation

ductility [5]. Less energy is needed for a brittle fracture than a ductile fracture; hence a brittle failure typically occurs through rapid crack propagation and minimal plastic deformation [6]. Brittle fracture occurs suddenly, without warning, and the failure is typically catastrophic-equipment can split rapidly or shatter into pieces that are thrown at high velocities. Figure 3 shows an example of a brittle fracture of a pressure vessel that was sudden and catastrophic. Brittle fracture resulted because of a small critical flaw at a repair weldment that had high material hardness and high residual welding stresses [7]. The sudden release of pressure, fragments, and contents is often hazardous to personnel and equipment nearby.

Key elements that can cause a brittle fracture are [8]

- Low fracture toughness

- High stress (residual or applied)

- Presence of a crack-like flaw or defect.

Fracture toughness is a quantitative way of expressing a material's resistance to brittle fracture when a crack or flaw is present. Low fracture toughness means that the material requires low energy to fail, especially in the presence of a small flaw or material defect. The conditions, mechanisms, and/or degradations that can cause the low toughness need to be considered. Vessels and pipes with low toughness do not fail unless subjected to high enough stresses to cause failure. High residual stresses, as high as the yield stress, can be present due to welding and heat treatments. High applied stresses can occur due to internal pressures or stress concentrations that occur at corners or notches. A cracklike flaw or defect can form during the fabrication or be 
created by a service-induced operating condition. When all three of these conditions are present, the risk for brittle failure is high. Therefore, it is essential to know whether these conditions are present, thus leading to a cold embrittlement condition. When a flaw is present or suspected to be present then, often a linear elastic fracture mechanics analysis is performed.

\section{Fracture Mechanics Methodology}

Brittle fractures, similar to those mentioned above are avoided using a linear elastic fracture mechanics design approach. This approach considers that the structure, instead of being defect free, contains a crack. The governing structural mechanics parameter when a crack is present, at least in the linear elastic approach, is an entity called the stress-intensity factor. This parameter, which is conventionally given the symbol $K$, can be determined from a mathematical analysis that combines the applied stress and the shape and the orientation of the crack [9]. For a relatively small crack in a simple structure, an analysis of the flawed structure can be approximated using this equation:

$K=1.12 \sigma \max (\pi a)^{0.5}$,

where $a$ is the depth of the crack and $\sigma$ is the stress that would occur at the crack location in the absence of the crack. The basic relation in fracture mechanics is one that equates $K$ to a critical value. This critical value is often taken as a property of the material called the plane-strain fracture toughness, conventionally denoted as KIc. When equality is achieved between $K$ and $K \mathrm{Ic}$, the crack is presumed to grow in an uncontrollable manner. Hence, the structure can be designed to be safe from fracture by ensuring that $K$ is less than $K$ Ic. The Liberty warship fractures are a classic example of a structural failure occurring because $\mathrm{K}$ exceeded $K \mathrm{Ic}$, resulting in uncontrolled crack growth. In fracture mechanics, the size of a crack is the dominant structural parameter. It is the specification of this parameter that distinguishes fracture mechanics from conventional stress analyses. Structures using reasonably tough materials (high $K \mathrm{Ic}$ ) and having only small cracks (low $K$ ) will behave by conventional strength of materials behavior. Conversely, if the material is brittle (low KIc) and strong (high $\sigma_{Y}$ ), the presence of even a small crack is likely to trigger fracture.

\section{Identifying Brittle Fracture Features}

One good way to understand and manage brittle fracture is when a vessel fails, immediately conduct a failure analysis. When performing the analysis, macroscopic and microscopic features can be useful in determining whether the failure was a brittle fracture or ductile fracture. Brittle fracture features are very distinct and different from a ductile failure. Some macroscopic things to look for as a failure analyst when examining a brittle fracture are:

- Little to no deformation or yielding

- Very small amount or no shear-lip is present

- Directional fracture features, such as Chevron markings that can indicate the direction of the crack propagation

- Presence of a stress concentration, small flaw, or defect at the origin.

Table 1 describes a comparison of the brittle fracture features to a ductile fracture feature. Figure 4 illustrates the different fracture planes for a ductile and brittle fracture.

First it helps to recognize the gross macroscopic differences between ductile and brittle fractured components. Figure 5 shows gross bulging that resulted in a steel pressure vessel shell that was $112 \mathrm{~mm}$ (4.4-inches) thick, after the shell was over-heated on the inside due to high heat condition on the inside surface [10]. Such gross deformation often accompanied by shear lips on the fracture itself is a good indication that the failure was not brittle, but was ductile.

In contrast, some components fail without any shear lips, reduction in thickness, or gross distortion, but they often contain directional features that can point back to the origin.

Table 1 Comparison of Brittle and Ductile Macroscopic Fracture Features

\begin{tabular}{lll}
\hline Categories & \multicolumn{1}{c}{ Ductile fracture } & \multicolumn{1}{c}{ Brittle fracture } \\
\hline Deformation pattern & Deformation and bulging & Little or no deformation \\
Fracture duration & Long time for failure & Short time for failure \\
Energy for fracture & Great energy for failure & Less energy for failure \\
Tension failure & $45^{\circ}$ shear & $90^{\circ}$ fracture \\
Torsion failure & $90^{\circ}$ fracture & $45^{\circ}$ fracture \\
Fracture features & Dimpled, fibrous fracture & Cleavage, faceted fracture, chevron marks \\
\hline
\end{tabular}


Fig. 4 Comparison of the fracture planes for ductile and brittle fractures in a pressure vessel

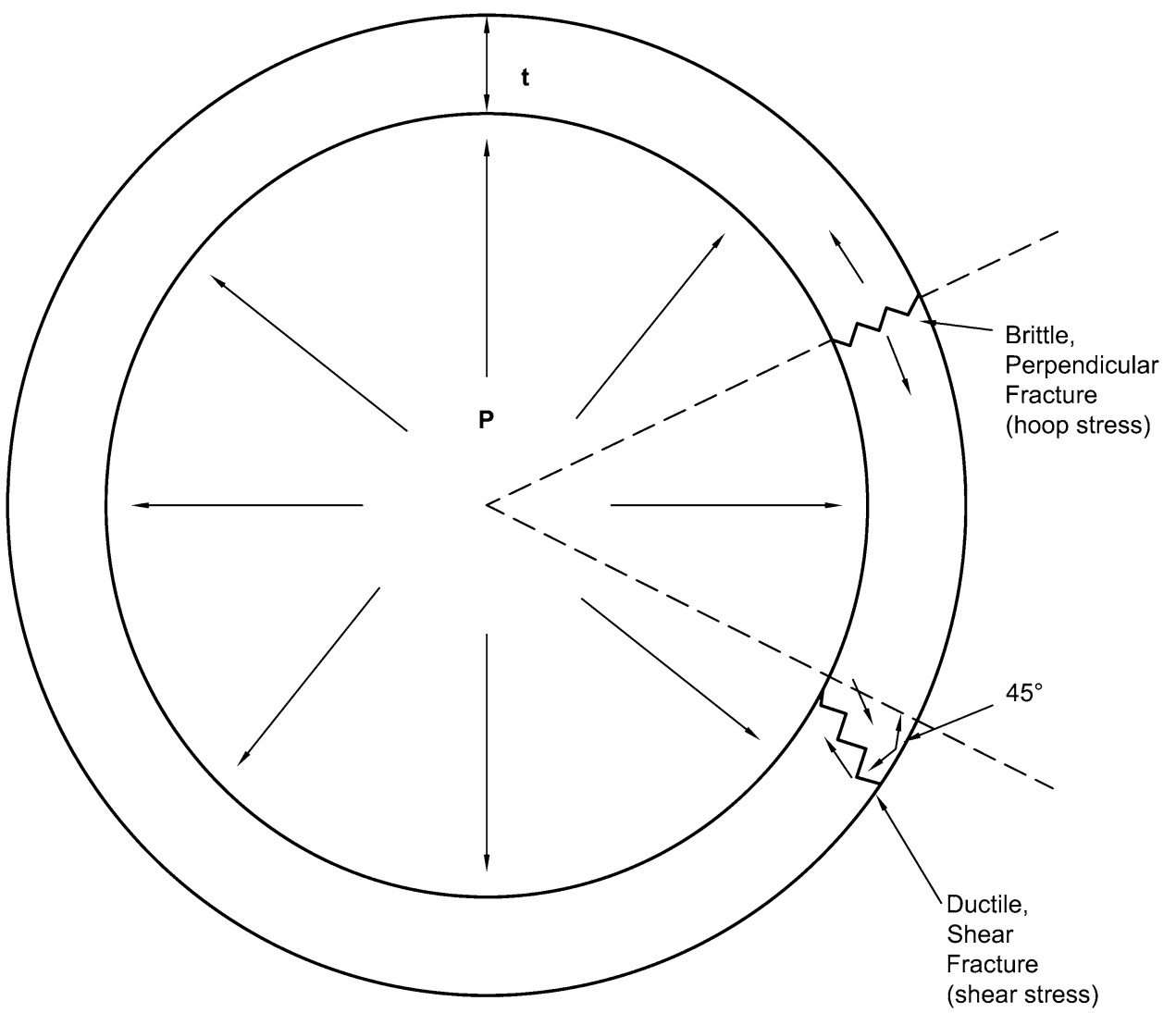

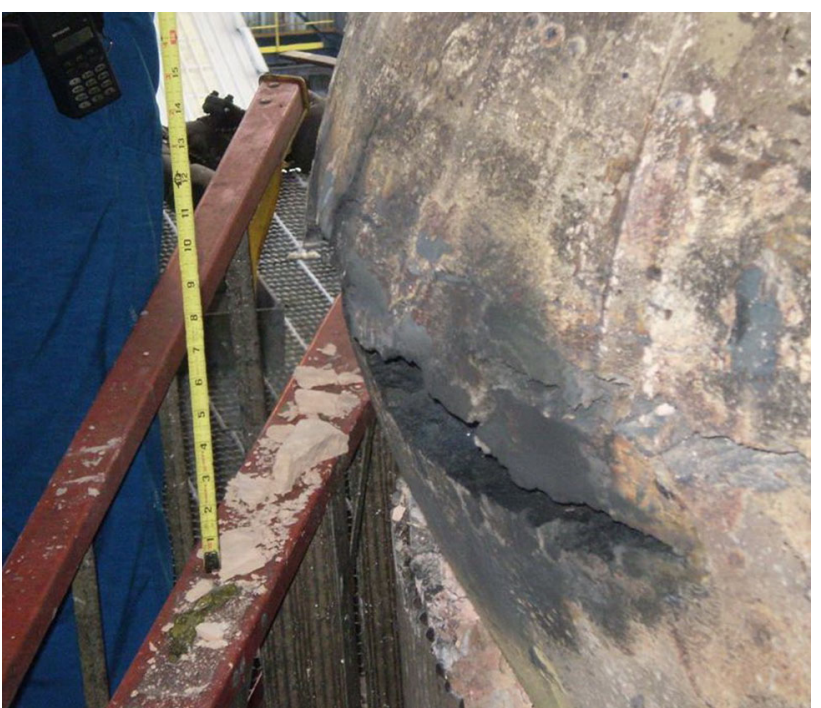

Fig. 5 Ductile fracture in a 112-mm (4.4-inch)-thick steel pressure vessel shell indicated by extensive bulging and deformation that preceded the fracture

Figure 6 shows the directional V-shaped chevron markings that point back to the origin of the fracture. Also notice the flat fracture and the absence of a shear-lip and no elongation or stretching, indicating a brittle fracture. Often there is a crack-like flaw or defect or feature at the origin of a brittle fracture that would be of little or no consequence,

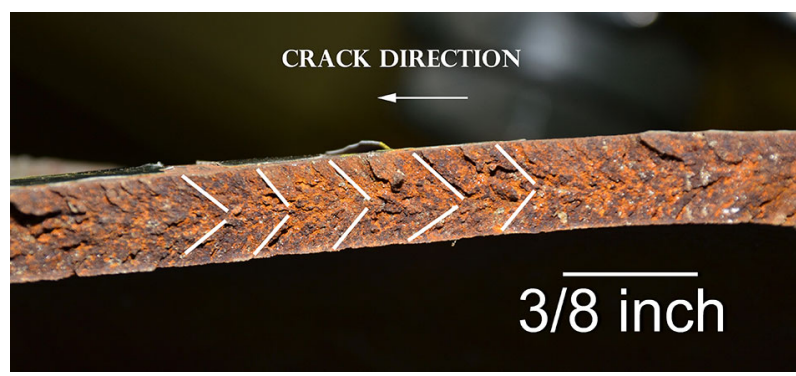

Fig. 6 V-shaped chevron marks found on a pressure vessel brittle fracture surface indicating the direction of crack propagation

if the component had operated at ductile temperatures. Because of that flaw or feature, brittle fractures usually occur below yield stress and there may be no deformation present.

Often it is necessary to examine the fracture using a scanning electron microscope. When ductile fractures are examined using a scanning electron microscope, the ductile fracture will usually exhibit ductile dimples as shown in Fig. 7. When tested below its ductile-to-brittle transition temperature, a normally ductile material may exhibit a brittle fracture with intergranular pattern or a cleavage fracture or a combination, as shown in Fig. 8. The ductileto-brittle transition temperature is discussed in more detail in the next section. 


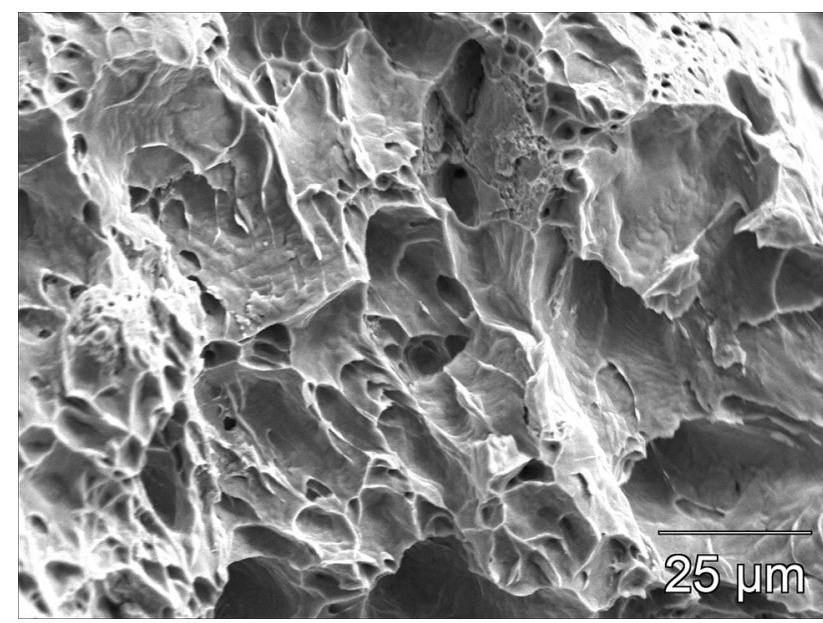

Fig. 7 Classical ductile fracture features for a steel that failed above the ductile-to-brittle transition temperature

\section{Brittle Fracture and Material Behavior}

Brittle fractures in pressure vessels often are associated with the brittle behavior of carbon or low-alloy steels. Although more likely to occur at atmospheric or subfreezing temperatures, brittle fractures can also occur at elevated temperatures if the metal has become embrittled by microstructural or metallurgical changes. In carbon and low-alloy steels, metallurgical characteristics imparted during manufacture or during usage may be a consideration if they cause the ductile-to-brittle transition temperature to be near or above the ambient temperature experienced by the vessel during operations and especially during hydrostatic testing. Poor quality steel or poor welding practice applied to pressure vessels can cause brittle fracture. The presence of residual welding stresses and reduced toughness can increase the risk of brittle fracture.

Carbon steel and alloy steel, unlike aluminum alloys and austenitic stainless steels, can change ductility based upon exposure temperature and when subjected to high load or dynamic load conditions. Steels have a unique toughness at a given temperature. A Charpy impact energy test is a simple indicator of fracture toughness. A typical impact energy curve or Charpy curve is shown in Fig. 9. Curve A shows that as the temperature drops, so does toughness and the energy required causing fracture. There is also a transition temperature from ductile-to-brittle fracture, often referred to as the ductile-to-brittle transition temperature (DBTT). Curve B shows a similar type of curve, but shifted to the right. This material has a higher DBTT and a lower toughness at a comparable temperature. Curve B could be representative of vintage steel, similar to those used for the Liberty ships and the molasses tanks, manufactured before treatments to improve brittle properties were implemented in the industry. Other parameters discussed in this article

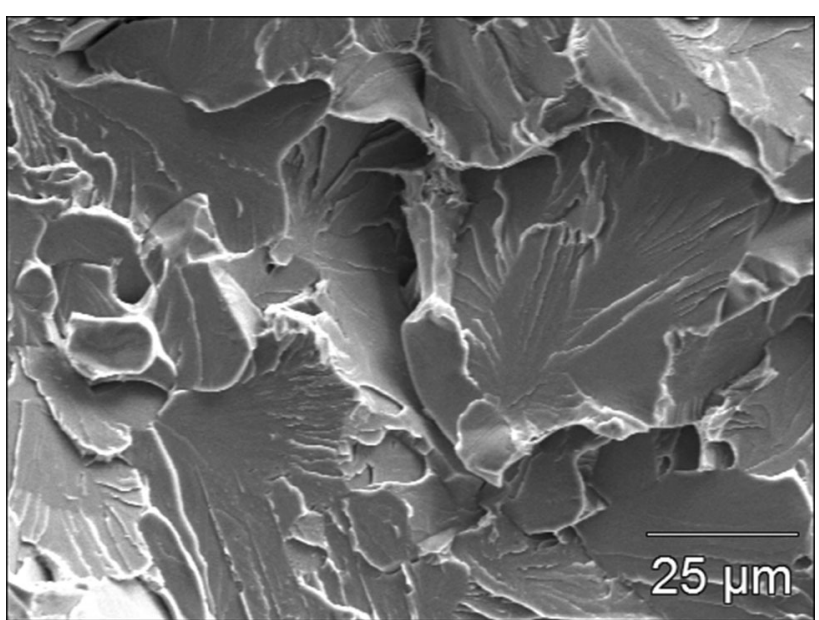

Fig. 8 Classical brittle cleavage fracture features for a steel that failed below the ductile-to-brittle transition temperature

can reduce the toughness of the material and thus shift the curve.

Several material and fabrication factors can affect steel behavior at low temperatures and can be optimized to avoid brittle fracture. These factors include the following:

- Steels with higher carbon weight percent can have lower toughness, either in the as-manufactured condition or due to carbon contamination from exposure to certain environments during use.

- Cleanliness of the steel affects the properties. For improved toughness, use steels with low weight percentages of sulfur and phosphorous. Older steel grades can have higher impurities and lower toughness.

- Non-stress relieved steels have lower toughness than stress-relieved steels.

- Welded materials with coarse grains can have lower toughness.

- Thicker steels such as those used for thick-walled pipe or vessels can have lower toughness.

\section{Pressure Vessel and Piping Codes}

Pressure vessels are typically designed to meet certain code requirements which can help reduce the risk of brittle fracture. Construction codes, such as the ASME B31.3 for piping [11] and ASME Section VIII for vessels [12], provide extensive rules for carbon steel and alloy steel materials that are subject to low temperatures.

For new equipment, brittle fracture is best prevented by using the current ASME Boiler and Pressure Vessel Code to specify and incorporate materials designed specifically for low temperature conditions, including upset and autorefrigeration events. 
For existing equipment, especially that manufactured prior to 1987 , a brittle fracture assessment may need to be performed. Some of the earliest codes were deficient in heat treatment requirements or they may not have required stress relief at all. The design temperature of vessels prior to 1987 allowed the use of carbon steels and alloy steels to $-29{ }^{\circ} \mathrm{C}\left(-20{ }^{\circ} \mathrm{F}\right)$ without the need of impact testing. If less than $-29^{\circ} \mathrm{C}\left(-20^{\circ} \mathrm{F}\right)$, impact testing was required. But after 1987, the pressure vessel code added rules including eliminating the impact testing exemption at $-29{ }^{\circ} \mathrm{C}$ $\left(-20^{\circ} \mathrm{F}\right)$ and implemented a minimum design metal temperature (MDMT). The MDMT of a vessel is the minimum metal temperature in which the vessel can sustain its full design pressure without having to be impact tested. Because of the concern about brittle fracture in carbon steel and alloy steels even above $-29^{\circ} \mathrm{C}\left(-20^{\circ} \mathrm{F}\right)$, modifications to the code now account for the lowest operating temperature, auto-refrigeration, and process upsets.

For example, for a $0.5^{\prime \prime}(13 \mathrm{~mm})$ nominal thickness vessel made from an older grade carbon steel material, the vessel could be acceptable at $-29^{\circ} \mathrm{C}\left(-20^{\circ} \mathrm{F}\right)$.
Fig. 9 Charpy impact curves showing the transition from a ductile behavior to a more brittle behavior as the temperature decreases
Fig. 10 Minimal allowable temperature (MAT) based on the material thickness and grade of material $[15,16]$
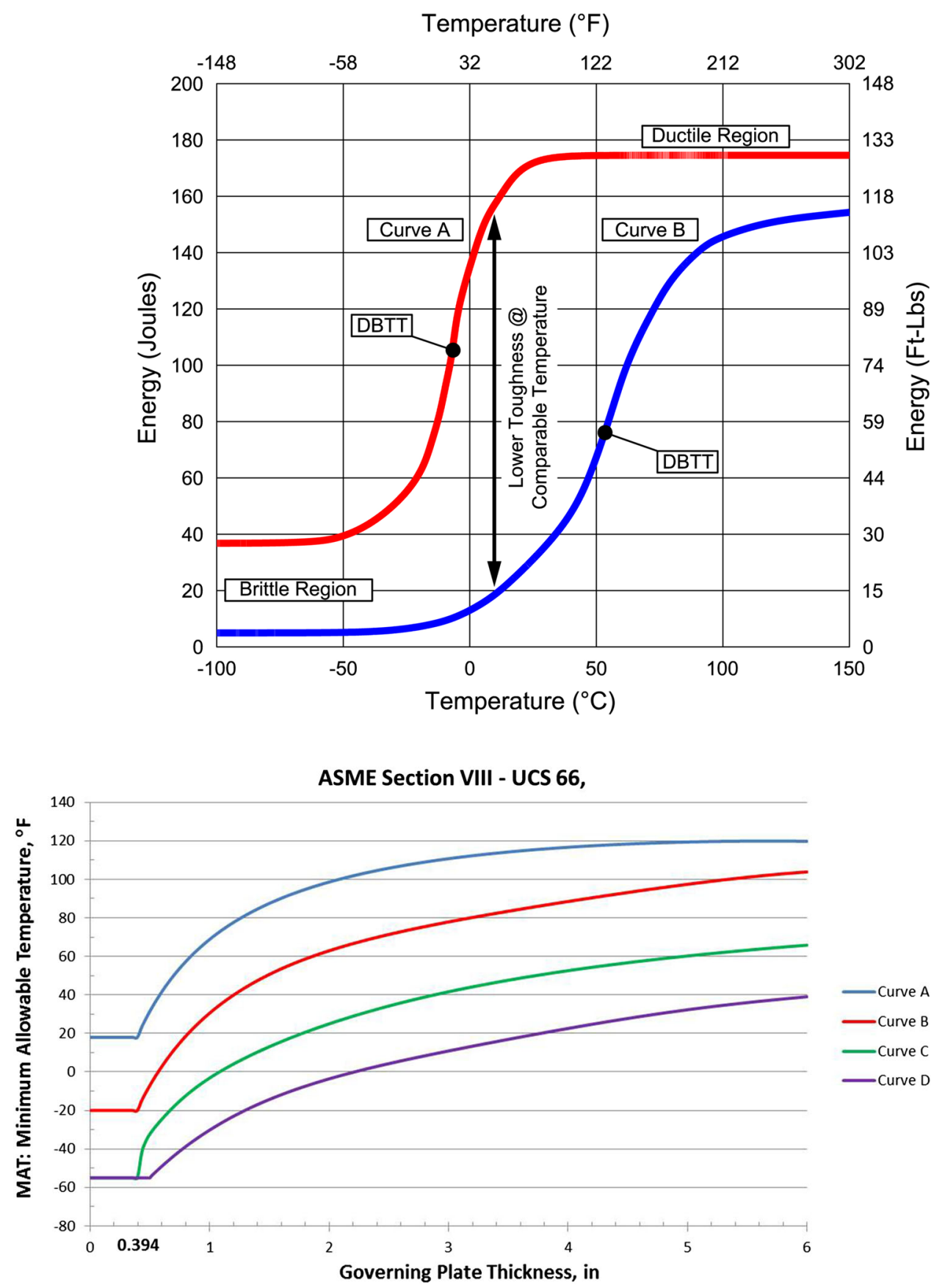
However, as the material thickness of the vessel increases, the allowable temperature to avoid brittle fracture also must increase, as shown in Fig. 10 [13, 14]. Curve A represents a material that has potentially poor toughness properties; while Curve D represents a material that has improved toughness. If the operating temperatures are held below that minimum allowable temperature, then there is a risk of brittle fracture. To avoid this, process controls have to be established in order to regulate the temperature, or a material upgrade may be necessary, or the vessel pressure may have to be reduced to reduce the wall stresses.

In some situations, vessels have failed due to cold water conditions during a hydrotest. Disruptive brittle failures of pressure vessels were reported between 1960 and 1970. Most of these failures occurred during the hydrotesting [15]. For example, a heavy-walled loop separator failed during a hydro test because the water was too cold. During modifications to add a level nozzle, all necessary weld procedures including stress relief were performed properly. The vessel was prepared for hydrotesting by filling it with water, but the hydrotest was discontinued as night was falling. The next morning, the temperatures were cool. As the hydrotest pressure was again increased, the vessel cracked. During the cool night, the metal temperature had fallen below the minimums for this heavy wall.

As mentioned, the presence of flaws, high residual stresses, and a reduction in toughness can all result in a brittle fracture during hydrotesting where pressures above the design are introduced. For such applications, consider using water temperatures above DBTT. The ASME Code [16] procedures include precautions to keep the vessel in the ductile range, including temperature of the vessel $30{ }^{\circ} \mathrm{F}$ above the MDMT, and ensuring the vessel and the hydrotest fluid are at the same temperature. Other codes offer procedures indicating using temperatures higher than $60{ }^{\circ} \mathrm{F}$ [17] or at least $30^{\circ} \mathrm{F}$ greater than the MAT. The appropriate codes should be reviewed for full details on safe and effective hydrotest procedures to avoid brittle fracture.

\section{Risk Management Practice: Assessment of Brittle Fracture}

\section{Brittle Fracture Risk Factors}

Knowing the risk factors can help in preventing brittle fracture when doing a brittle fracture assessment. Evaluation of brittle fracture hazards may be difficult, yet necessary. Attempts to verify that the equipment or pressure vessel is suitable for service can reveal a lack of proper materials or testing documentation when determining the material properties. In general, potential pressure vessel process risks that may be prone to cold temperature embrittlement issues may include the following:

- Processes in refrigeration service

- Cryogenic storage and cold box systems

- Low temperature exposure

- Liquefied-gases (including nitrogen and ammonia)

- Depressurization events

- Inferior, vintage grade steels (before 1987)

- Thick-walled pressure vessels

- Hydrotesting with cold water, below the DBTT.

Some questions to consider when assessing the risk for brittle fracture are

- Have the drawings and the materials of construction been verified?

- Was Charpy testing done during fabrication and if so, at what temperature?

- Have modifications to the vessel, such as welding, occurred after the vessel was installed that could drop the toughness of the material?

- Have the process conditions changed, increasing the possibility of low metal temperature?

- Were the vessels built before 1987?

- Has brittle fracture been considered in a Process Hazard Analysis (PHA) review, because either the temperature is lower than the original design or a depressurization event could occur, which drops the exposure temperature?

Process safety management practices, such as process hazard analysis (PHA) and safe operating limits or integrity operating window limits may reveal conditions where equipment is being operated below its MDMT, or the equipment MDMT is not clearly communicated to the operators.

\section{Repairs}

Repairs or improper welds can introduce stress points that lead to brittle failure or brittle material behavior if proper procedures are not followed. For example, a 46-cm (18inch)-long crack was found in a carbon steel as-forged nozzle on a vessel that was arc-gouged. Failure occurred after 5 years in service during a cold-start-up procedure. The crack initiated at the arc gouge notch due to a very hard zone (HRC 54) that was not removed after arc gouging. An initial flaw and poor toughness during the cold start condition resulted in cracking (Fig. 11) [18]. 


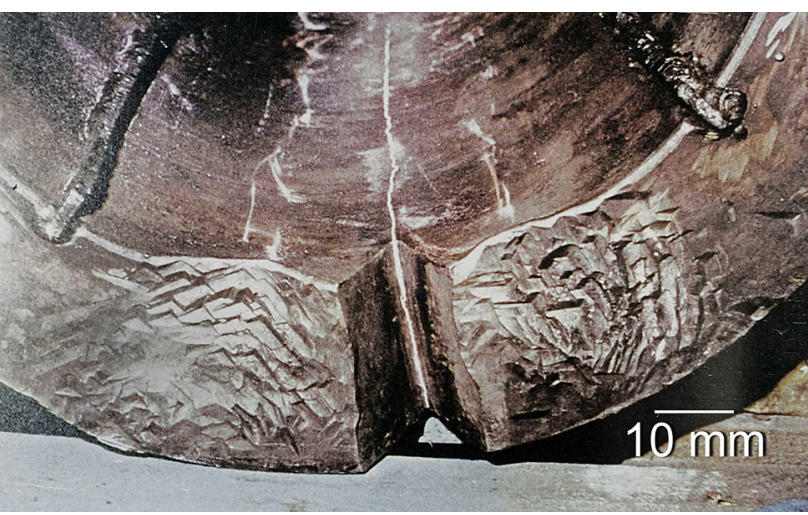

Fig. 11 Arc-gouged notch and a hard region causing a long crack on as-forged nozzle

\section{Assessment of Brittle Fracture}

For existing equipment, normal inspection practices cannot identify the risk of equipment failure by brittle fracture. In 2007, a joint committee formed by ASME/API released the standard known as API 579-1/ASME FFS-1, which covers fitness-for-service (FFS) assessments, and includes Part 3-Assessing of Existing Equipment for Brittle Fracture. The API methodology incorporated some of the design guidelines of ASME piping and pressure vessel codes and has also been widely used and accepted in refinery and other petrochemical industries [19].

For existing equipment, especially that manufactured prior to 1987, a brittle fracture assessment may need to be performed. A cold temperature brittle fracture engineering

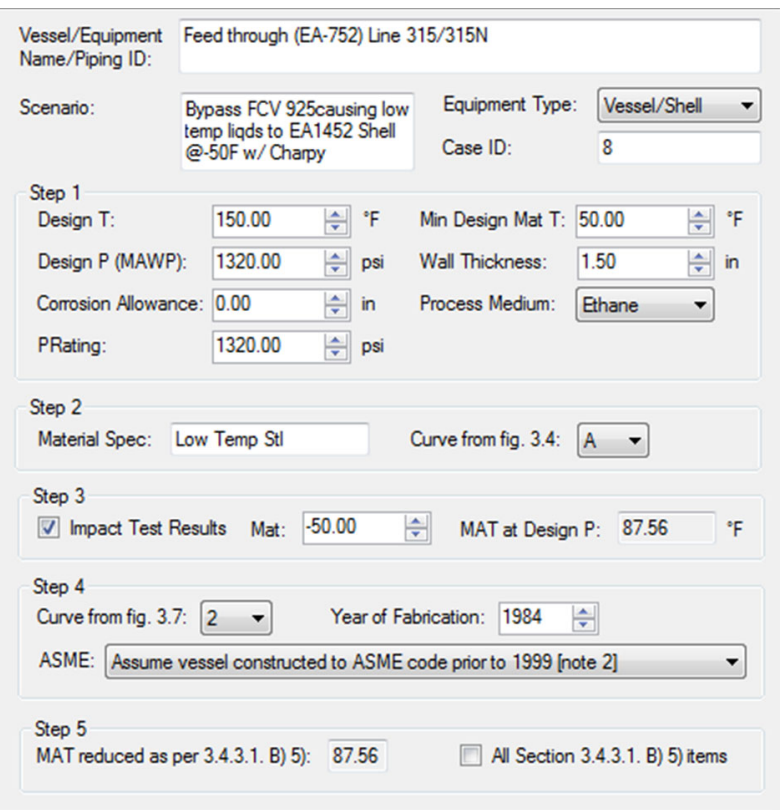

Fig. 12 BakerRisk Software input screen showing the parameters considered for brittle fracture assessment assessment [20] as outlined in the API 579-1/ASME FFS-1 Part 3 is considered a "best engineering practice." A cold embrittlement review is a multi-disciplined review that assesses the materials used and the operating conditions under which they are used, in order to reduce the risk of a brittle fracture at facilities.

A cold temperature brittle fracture engineering assessment as outlined in the API 579-1/ASME FFS-1 Part 3 evaluates the safeguards in place to control pressures and temperatures required in order to avoid low temperature conditions and assess the material behavior of the equipment. Figure 12 shows a spreadsheet of parameters considered in a review.

Figure 13 shows a plot of the equipment minimum allowable temperature (MAT) as a function of pressure and stress. The assessment identifies potential scenarios for low temperature excursions and then reviews the process and equipment condition input from the plant to determine the critical exposure temperature (CET). The CET is the lowest metal temperature that the material is exposed to in the coldest scenario. The CET is derived from either the operating or atmospheric conditions at the maximum assumed combination of pressure and primary supplemental loads. The shell, head, and nozzles are assessed as shown in Fig. 14.

The CET is compared to the equipment MAT. This plot and the determination of the MAT can be generated by using a software package for cold temperature embrittlement reviews based on criteria using API 579-Fitness for Service, Part 3.

Once a decision is made to perform a FFS engineering assessment, an evaluation may involve the following:

- Review selected low temperature scenarios that were identified from previous PHAs.

- Review the low temperature alarm settings, interlocks, and overrides that were provided. All alarms less than a certain temperature can be considered for any cold embrittlement scenarios.

- Screen the process flow diagrams (PFD's) and piping and instrument diagrams (P\&IDs) for potential cold embrittlement scenarios, focusing on material limits, process information, instrumentation and controls, and potential risks. Startup, shutdown, and normal operations can be considered in identifying potential low temperature scenarios. The review can also consider material spec changes identified on the P\&IDs. This is considered a screening Level 1 review.

- Review the equipment drawings and manufacturers data report form (U1) for design limits, thicknesses, and materials of construction.

- Perform analysis of equipment to determine Minimum Allowable Temperature curve based on information in equipment drawings and U1s. Figure 14a depicts how the MAT curve can vary for equipment components based on respective material, thickness, etc. Note that 
Fig. 13 Plot of the MAT curve as a function of decreasing pressure compared to the CET
Min Allowable Temp $\left({ }^{\circ} \mathrm{F}\right)$ vs. Operating Pressure

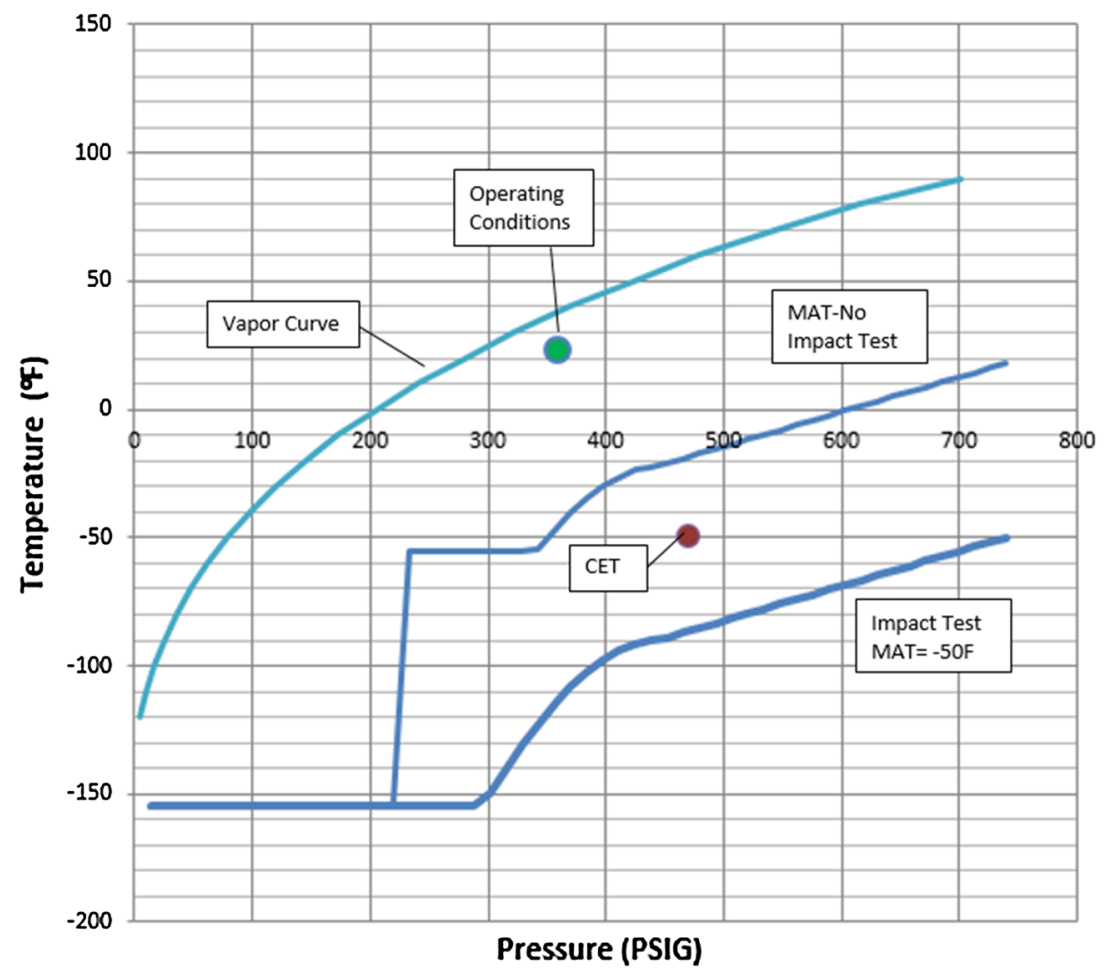

only one of the three nozzles, Nozzle A, is represented. In this particular illustration, the shell, head, and nozzle are acceptable at the operating conditions, assuming operating conditions are above the MAT curve.

- Assess the potential cold embrittlement concerns that are identified, utilizing process modeling and equipment minimum allowable temperatures. Establish critical exposure temperatures based upon either the known process conditions or using the plant's simulation models. Compare critical exposure temperatures to the minimum allowable temperatures. Figure $14 \mathrm{~b}$ illustrates how given components (shell, head, nozzle, etc.) may not be acceptable at the CET. This particular illustration shows that the MAT curve for the shell and nozzle is above the CET [or borderline] and therefore may require additional review and/or process controls. This additional review is considered a screening Level 2 review.

- Consider conducting a Level 3 assessment if the equipment is not within the acceptable criteria of the screening Level 1 and Level 2 reviews. A Level 3 detailed assessment involves a fracture mechanics methodology and approach.

\section{Safeguards Against Brittle Fracture}

After performing a brittle fracture assessment, a facility or plant may have a varying range of risk exposure based on certain generalized risk factors (Year of Fabrication, Material Type of Equipment, presence/absence of PostWeld Heat Treatment, presence/absence of Material Impact Testing, or presence/absence of Hydro Testing). Recommendations to reduce potential risk of cold temperature embrittlement fracture may include the following:

- Add process safeguards

- Change or upgrade the material

- Modify low temperature alarms

- Alter process critical exposure temperature

- Require heat treatment of material

- Perform impact testing of material

- Conduct hydrotesting of vessel.

\section{Case Studies}

The following case studies show how brittle fracture assessments can be performed on existing pressure vessels at a production facility.

High-Pressure Purge Vessel

A high-pressure purge gas separator was assessed for both operating and shutdown conditions. Constructed in early 1960s, the vessel has a 33-mm (11/2-inch)-thick shell and heads; A106 and A234, respectively, and is stress relieved. 


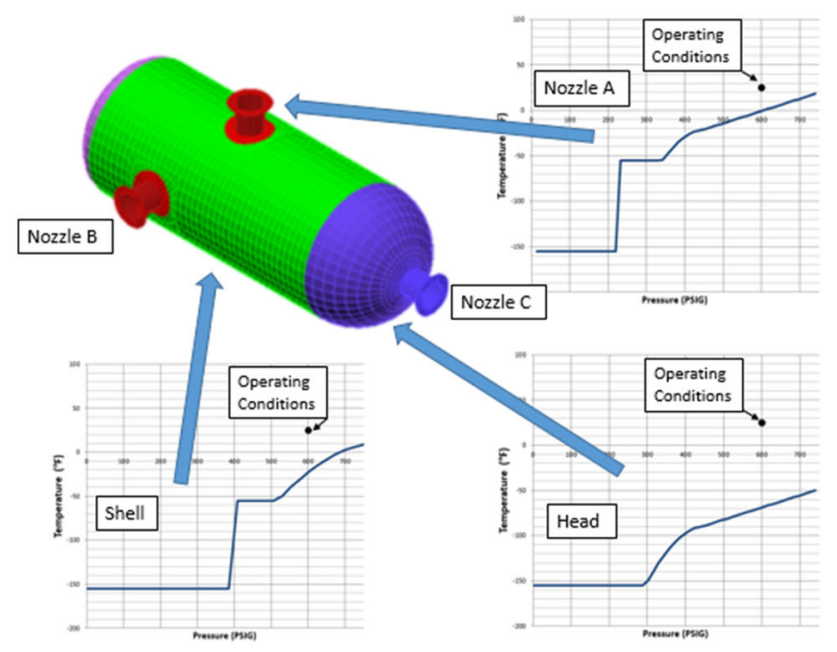

(a) Component MAT Curves

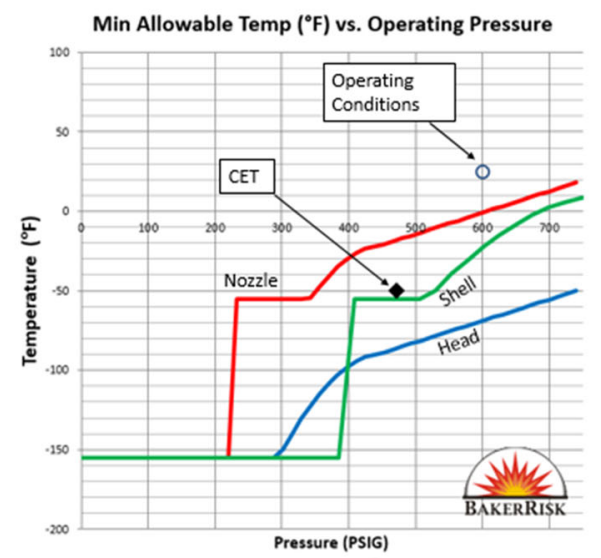

(b) Superimposed MAT Curves

Fig. 14 Brittle fracture review for a vessel assesses nozzles, shells, and heads made of different materials and different thicknesses. (a) Depicts MAT of equipment components in relation to operating conditions and (b) illustrates how risk for cold temperature embrittlement may develop if the temperature drops to the CET

With design conditions of $-4{ }^{\circ} \mathrm{C}\left(25^{\circ} \mathrm{F}\right)$ and maximum allowable working pressure (MAWP) of $34 \mathrm{MPa}(4950$ psig), a MAT curve was developed which identified that there may be a risk of cold temperature brittle failure at operating conditions [26 MPa (3900 psig), $\left.-4{ }^{\circ} \mathrm{C}\left(25^{\circ} \mathrm{F}\right)\right]$, see solid line in Fig. 15. Discussion identified that $-33^{\circ} \mathrm{C}$ $\left(-28^{\circ} \mathrm{F}\right)$ was likely the coldest temperature the line would experience during a depressurization event. A review of the available documentation could not verify that Charpy impact testing was performed on the equipment. As the equipment is below the acceptable criteria of the screening Level 2 reviews, a Level 3 detailed fracture mechanics FEA assessment may be prudent. Alternatively, process controls or low temperature alarms can be implemented to stay above the curve, or the decision can be made to replace this relatively small vessel with one that is known to have appropriate specifications and documentation (dashed line in figure).

\section{Process Separator Vessel}

A high-pressure separator was assessed for both operating and shutdown conditions. Constructed in the early 1960s, the vessel has $95-\mathrm{mm}$ (3 3/4-inch)-thick heads with A212 Gr B (Fire Box Quality (FBQ)) per ASTM A300, which required a special treatment of a fine-grained steel with $-46{ }^{\circ} \mathrm{C}\left(-50{ }^{\circ} \mathrm{F}\right)$ guaranteed toughness properties; see solid line in Fig. 16. Standard grade A212 without special heat treatment and low toughness properties is considered to be vintage steel that historically has shown material properties susceptible to brittle failure at cold temperatures, see dashed line in figure. With design conditions of $-33^{\circ} \mathrm{C}$ $\left(-28^{\circ} \mathrm{F}\right)$ and MAWP of $35.6 \mathrm{MPa}$ (5170 psig), a MAT curve was developed (solid line in figure), which determined the vessel was acceptable at the operating condition and the depressurization event with the fine-grain material. This information was valuable to the facility as it gave them confidence in their vessel, knowing the possibility of the risk associated with the thick vintage steel. In this case, the fact that the material was impact tested provided the surety for low risk of cold temperature brittle fracture. Any subsequent repairs, however, could require re-evaluation.

\section{Summary}

Brittle fracture is a potential concern in vessels, especially older or thicker vessels that may not have adequate toughness for all operating conditions. Certain process upsets, shutdowns, and start-ups can reduce the temperature enough that the vessel or pipe is exposed to temperatures that, although not cold, may be low enough to reduce toughness and cause failure at the residual and applied stress state.

Brittle failure is typically a high consequence hazard in a facility with pressure vessels. We have learned from history the risk factors that can cause brittle fracture. The risk factors that lead to brittle fracture for each vessel should be understood. Then, the possible hazards can be recognized in process hazard analyses, maintenance and mechanical integrity programs, engineering and management of change decisions, and in training. Analysis of the fracture features of vessels that have failed will help in an understanding of the causes of brittle fracture and how to mitigate those causes.

To understand and manage these risks, brittle fracture engineering assessments identify the potential hazards and possible safeguards for implementation that will 
Fig. 15 Minimum allowable temperature versus operating pressure for gas separator

Fig. 16 Minimum allowable temperature versus operating pressure for process separator vessel
Min Allowable Temp $\left({ }^{\circ} \mathrm{F}\right)$ vs. Operating Pressure
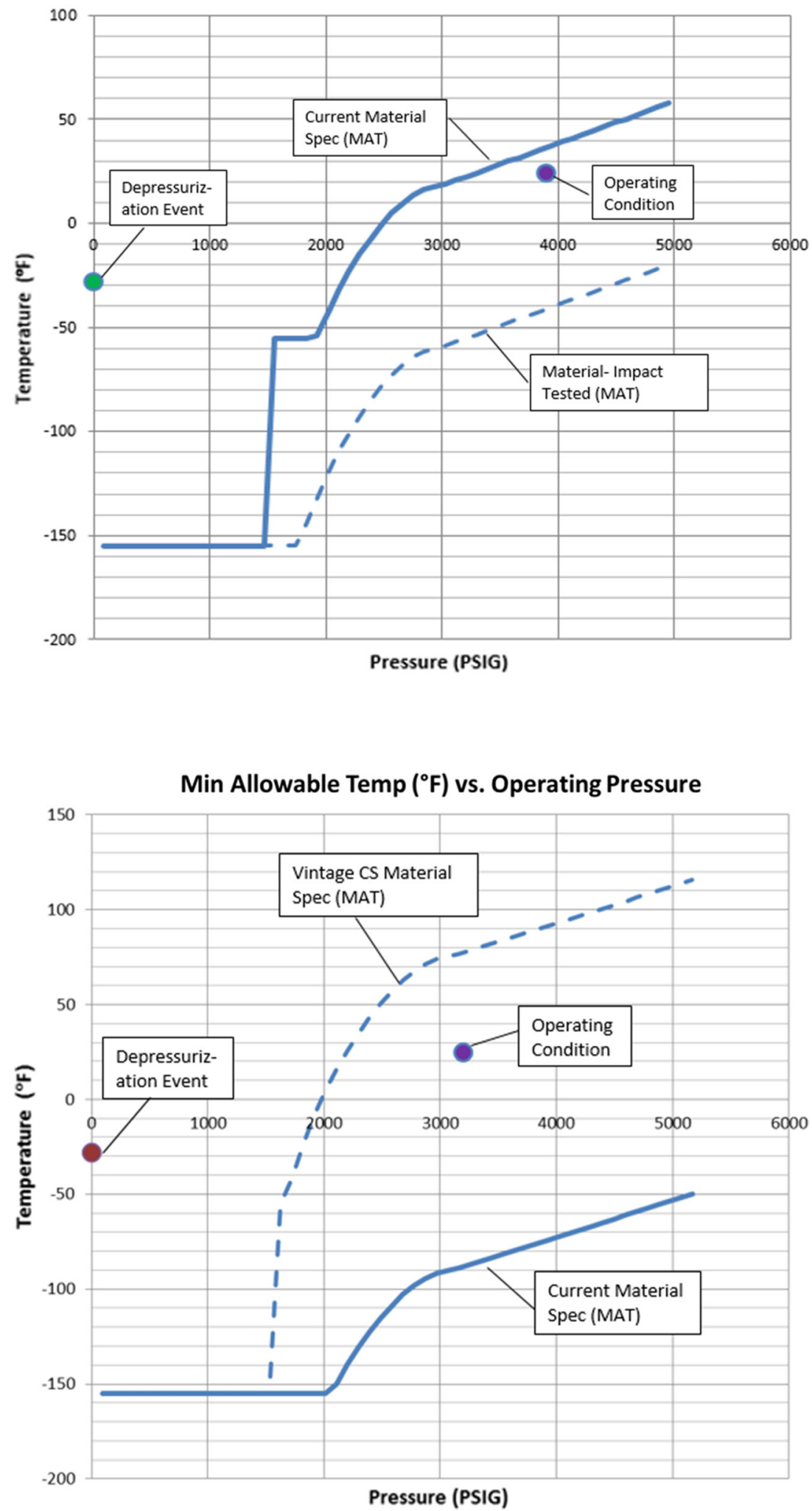

mitigate or prevent brittle fracture. Using proper assessments and application of the principles mentioned in this article, potential cold temperature embrittlement and brittle fracture risks can be identified and properly managed, helping to reduce the risk of brittle failure and fracture. 


\section{References}

1. D.J. Benac, in "Failure Analysis and Life Assessment of Structural Components," Failure Analysis and Prevention, vol. 11. ASM Handbook, (ASM International, Materials Park, 2002) p. 228

2. D.J. Wulpi, Understanding How Components Fail, 3rd edn. (ASM International, Materials Park, 2013), pp. 83-85

3. H. Lonsdale, in Ammonia Tank Failure-South Africa, vol. 17. Ammonia Plant Safety (AIChE, 1975) pp. 126-131

4. D.J. Benac, D. Shaffer, D. Wood, Managing Cold Temperature and Brittle Fracture Hazards in the Ammonia-Related Industries. in AlChE $60^{\text {th }}$ Annual Safety in the Ammonia Plants \& Facilities Symposium, 2015

5. API 571, Damage Mechanisms Affecting Fixed Equipment in the Refining Industry, 2nd edn. 2011

6. ASM Handbook Failure Analysis and Prevention, vol. 11 (ASM International, Materials Park, 2002) p. 1062

7. M. Picou, Failure of a Molecular Sieve Vessel Resulting from a Defective Weld Repair. in Ammonia Technical Manual, 2002, pp. 133-144

8. B. Macejko, Is your plant vulnerable to a brittle fracture? Hydrocarbon Process. 93, 67-77 (2014)

9. D.J. Benac, in "Failure Analysis and Life Assessment of Structural Components," Failure Analysis and Prevention, vol. 11. ASM Handbook, (ASM International, Materials Park, 2002) p. 229
10. D.J. Benac, D.B. Olson, M. Urzendowski, High-temperature stress relaxation cracking and stress ruptured observed in a coke gasifier failure. J. Fail. Anal. Prev. 11(3), 251-264 (2011)

11. ASME Code for Process Piping B31.3-2004

12. ASME Boiler Pressure Vessel Code Section VIII Division 1 Rules for Construction of Pressure Vessels, ASME 2013

13. ASME Section VIII Division 1-2007, Standard Hydrostatic Test, UG-99 (h)

14. NB NBIC 3 (2007): National Board Inspection Code, Part 3, Section 4, Repairs and Alteration, 4.4.1 (a) (3)

15. J.F. Lancaster, Failures of boilers and pressure vessels. Pressure Vessel Pip. 1, 155-170 (1973)

16. Fig. USC-66 Impact Test Exemption Curve, ASME Section VIII Division 1-2007

17. Fig. 323.2.2A Minimum Temperatures Without Impact Testing for Carbon Steel Materials, ASME B31.3-2004

18. D.J. Benac, in "Failure Analysis and Life Assessment of Structural Components," Failure Analysis and Prevention, vol. 11. ASM Handbook, (ASM International, Materials Park, 2002) pp. 232-233

19. R.E. King, Auto-refrigeration/brittle fracture analysis of existing olefins-translation of lessons learned to other processes. J. Hazard. Mater. 142, 608 (2007)

20. API 579-1/ASME FFS-1, Fitness for Service Part 3-Assessment of Existing Equipment for Brittle Fracture, 5 June 2007 